\title{
Zaum Box: New Music for Speaking Percussionist
}

\author{
Christopher Adler \\ Department of Music, University of San Diego \\ 5998 Alcala Park, San Diego, CA 92120 USA \\ e-mail: cadler@sandiego.edu \\ *Corresponding author: cadler@sandiego.edu
}

Published: 22 September 2020

Cite this article (APA): Adler, C. (2020). Zaum Box: New music for speaking percussionist. Malaysian Journal of Music, 9, 55-65. https://doi.org/10.37134/mjm.vol9.5.2020

\begin{abstract}
Zaum Box is a collection of compositions for solo speaking percussionist setting transrational Russian futurist sound poetry called zaum. Zaum arose among a small interdisciplinary group of artists, writers, musicians and thinkers who invented a beyond-rational language as part of the radical disruption of traditional artistic and expressive forms, necessary to bring about the accelerated experience of a technologically-driven future. The subgenre of contemporary concert music for solo speaking instrumentalist dates from the 1970's and has grown into a significant branch of the solo percussion repertoire. The composition of Zaum Box was founded on an extended period of research into zaum, futurism and Russian language. The complete set of compositions was produced as a limited-edition box set of uniquely formatted scores, which were realised by percussionist Katelyn Rose King in a set of ten videos. This article by the composer reviews all the phases of this project, including research and production, and examines the relationships between text, sound, music and theatricality in selected scores.
\end{abstract}

Keywords: composition, contemporary music, futurism, percussion, sound poetry

\section{Introduction}

Zaum Box is a collection of ten compositions for solo speaking percussionist commissioned by Katelyn Rose King and Alexv Rolfe, and composed by the author in 2015-16. Each composition may be performed singly, or any number of the compositions may be selected and performed as a set. This open-ended form was inspired by the Fluxkits of Fluxus artists, whimsical collections of objects presented as a boxed collection that facilitate the investigation of primary experience by the user who is invited to engage in a form of play (Higgins, 2002). The activation of the viewer of art as an engaged participant in the construction of experience, as posited by conceptual, event, and minimalist artists in the 1960's, here informs the relationship between composer, score and performer. The performer playing the work is engaged as an active participant in constructing a playful presentation, in concert performance or media representation, through the selection of movements and the manner of their presentation, through the interpretation of indeterminate aspects within each of the compositions, and through the potential theatricality of their realisation.

Research is a foundation of my compositional practice. This includes an ongoing study of the musical traditions of Thailand and Laos that has led to many cross-cultural compositions for Asian and Western instruments (Adler, 2007), and research into fractal mathematics and algorithmic composition (Adler, 2012). Zaum Box arose from open-ended research into Russian futurist art which has also inspired my works Violin Concerto (2013), Construct: for organ (2016) and Sensations of Metals (Dynamic Construction after Kazimir Malevich) (2019). It was in the course of this research that I 
learned of a branch of Russian futurist poetry called zaum, dating from 1913-1923, which explored a realm beyond conventional language. When I was commissioned to write a piece for speaking percussionist, where the performer reads a text while performing on their instrument, the zaum texts struck me as ideal. The ethos of futurism was already appealing to me, and the fact that they texts were largely nonsense, that is without a clear meaning or interpretation, made them a kind of sound poetry more akin to musical sound than to semantic poetry. Research into zaum, Russian futurism, and Russian language, then, became a foundation for and ongoing inspiration behind a three-year project which included the selection of specific texts, composition of music, preparation of scores including images of the original texts, manufacturing a limited-edition box set of scores along with supporting materials such as a guide to pronunciation, and finally the realisation of the ten compositions as videos to be publicly released. ${ }^{1}$

\section{Zaum and Russian Futurism}

Each composition in Zaum Box is a setting of Russian futurist transrational poetry, called zaum (заумь). The term, coined by Aleksei Kruchenykh, described the radical linguistic experiments of futurist poets, artists and playwrights between 1913 and 1923. It is formed from two words: $z a$-, meaning 'beyond', and -um, meaning 'mind' or 'intellect'. Zaum included word combinations beyond syntactical sense, invented words, the fragmentation of words into phonemes, and the obliteration of written language into abstract visual forms. This extraordinary evolution of poetry into visual and sonic abstraction took place over just a few years and was an early literary manifestation of the revolutionary shift from rational representation to the indeterminacy of subjective perception expressed by cubism and by subsequent artistic movements of the twentieth century. It is evidence of the radical investigation and rejection of conventions practiced by the Russian futurists.

Zaum was born among a tight community of futurists in Moscow, that came to be known as the cubo-futurists, including writers Aleksei Kruchenykh, Velimir Khlebnikov, Elena Guro, Vasily Kamensky, Igor Terentev, Vladimir Mayakovsky and David Burliuk, artists Olga Rozanova, Varvara Stepanova, Alexsandr Rodchenko, Kazimir Malevich and Vladimir Burliuk, and composer Mikhail Matyushin. The multi-disciplinary nature of this movement fuelled its radical aesthetic and repertoire of techniques, as poets, for example, envisioned disrupting language with the same techniques that futurist painters applied to representational images. And it led to collaborative book art taking particular prominence in the movement, in which painting and drawing, poetry, discourse, and even found object collage merged into creative product (Perloff, 2016). Hastily produced short-run manuscript booklets elucidated the futurist aesthetics of speed, dynamism, immediacy and ephemerality. These are evident in this fragmented and breathless excerpt from the 1913 manifesto The Word as Such (Kruchenykh \& Khlebnikov, 1988, p. 57), which also illustrates that the group of radicals was very attentive to defining its own membership:

1. that it be written and perceived in the twinkling of an eye! (singing splashing dancing, scattering of clumsy constructions, oblivion, unlearning. V. Khlebnikov, A. Kruchenykh, E. Guro; in painting, V. Burliuk and O. Rozanova).

2. that it be written tightly and read tightly, more uncomfortable than blacked boots or a truck in the living room (plenty of knotted ties and buttonholes and patches, a splintery texture, very rough. In poetry, D. Burliuk, V. Mayakovsky, N. Burliuk, and B. Livshits; in painting, D. Burliuk, K. Malevich.) $)^{2}$

Kruchenykh moved to Tiflis (Tbilisi, Georgia) in 1917, during the Russian revolution, and with him moved the centre of gravity of the movement. He joined with others there in the avant-garde including Ilya Zdanevich. By the early 1920's, the movement became reflective, focused on theorisation, and thereafter faded with the rise of politically-oriented movements such as constructivism and the newly-established Soviet Union (Janecek, 1996).

The first pure zaum poem, containing no intact Russian words, was Dyr bul shchyl, by Aleksei Kruchenykh, published in Pomada in 1913. Zaum was driven by the futurist fascination with speed and dynamism, and the belief that ordinary language could not keep up with the mind in a state of 
inspiration. Kruchenykh imagined the nonsense words as having a meaning that was hot and fluid, in contrast to the frozen, fixed meanings that shackled the expressive capability of rational language (Janecek, 1996). His poetry of sound forms explored the raw material of vocal sound while retaining the ability to disrupt perception through the tenuous associations of invented word-forms with existing words. Even within this single early example, the trajectory towards abstraction is apparent as nonsense words dissolve into individual sounds in a persistent triple rhythm.

$\begin{array}{ll}\text { Дир бул щыл } & \text { Dyr bul shchyl } \\ \text { убешщур } & \text { ubesh-shchur } \\ \text { скум } & \text { skum } \\ \text { вы со бу } & \text { vi so bu } \\ \text { р л эз } & \text { r l ez }\end{array}$

Zaum also appeared as a visual art, in paintings on found material by Varvara Stepanova and in paintings by Olga Rozanova. It was also expressed in bold typographical experiments by Vasily Kamensky (Tango with Cows, 1914) and Ilya Zdanevich (Lidantiu as Beacon, 1923). These experiments prefigured the creative typography in constructivist art and design of the 1920's. In addition, zaum was incorporated into full theatrical productions combining zaum texts, futurist costumes and staging, and music, such as Victory Over the Sun, produced in 1913, with libretto by Kruchenykh, music by Matyushin, prologue by Khlebnikov, and stage design by Malevich.

It was Aleksei Kruchenykh who led a dissolution of poetry into visual abstraction, as in Learn, Artists!, from 1917, in which individual letters take on the quality of rayonist or cubist forms and there is no conventional, linear approach to reading or sounding out the poetry (see Figure 5). The pages of F/Nagt, published in 1918, alternate between fragments of handwritten zaum enmeshed in visual constructions, and completely abstract forms expressive of futurist dynamism.

The Russian cubo-futurists were indebted to the Italian futurists for cultivating the ambition to capture by expressive means the dynamism and intensity of a rapidly technologising cultural present, and for staking theoretical positions in the form of manifestos, but they did not share Filippo Tommaso Marinetti's obsession with war and violence, and came to regard their own project as more advanced (Harte, 2009). The cubo-futurists sought to shatter the conventions of expressive language and art to enable humans to imagine a transformed world, and for they themselves to be transformed. It was this utopian vision of a human transformation that was taken up by the left and ultimately co-opted by totalitarian political programs (Groys, 2011). Zaum also had affinities with Dada, in the immediacy and automatism of nonsense writing, in the use of creative typography and visual design, and in a fascination with the primitive. While Dada looked to Africa (Burmesier et al., 2016), the Russian futurists looked to the ethnic tribes and diverse languages within the Russian empire. It was, in part, this nationalist sensibility that later motivated the rejection of zaum and Russian futurism as unsuited to establishment of an international proletarian political movement in post-revolutionary Russia (Janecek, 1996).

\section{Music for Speaking Percussionist}

In the 1970's, a subgenre of contemporary Western concert music emerged of works for solo instrumentalists who speak texts as they perform, combining poetry or storytelling with music. Throughout the $20^{\text {th }}$ century, the rapid development of new musical ideas and styles was accompanied by an intensification of virtuosity demanded of performers. The combination of spoken text with instrumental performance was an innovative new form of virtuosity beyond conventional instrumental technique, and called for the performer to attend to two, somewhat distinct streams of activity, and ensure that both are realised with a suitable level of craft and artistry. One of the first such works is Failing (1975), by Tom Johnson, for contrabass, in which the spoken text explicitly discusses the impossibility of maintaining both speech and music as the piece becomes increasingly difficult.

Another early work, Toucher (1973), by Vinko Globokar, for percussion, examines the relationship between voice and instrument by structuring the percussion part as a realisation or sonification of the spoken text with identical rhythm performed in unison. The performer is called upon to select instruments that will imitate the timbres of the vocal sounds as realised by the performer (Schick, 2006). Georges Aperghis composed multiple works for speaking percussionist in the 1970's 
including Le Corps à Corps (1978) and Graffitis (1980). In these works, playing and vocalising are integrated into a theatrical experience in which the performer is emotionally and physically involved, and speech and vocalisations are delivered with an exaggerated theatricality. Also in a theatrical vein, Hans Werner Henze's Prison Song (1971) presents the percussionist trapped within a prison of percussion surrounding them on all sides.

In the 1980's, the subgenre of compositions for solo speaking percussionist grew rapidly. American composer Stuart Saunders Smith composed a number of pieces that make specific theatrical demands upon the performer, including physical movements and conveying specific emotional characters while speaking and performing on instruments. The texts include a mixture of language and nonsense vocal sounds. These include Songs I-IX (1980-82), By Language Embellished, I (1984), “...And Points North” (1987-90), and Tunnels (1988). Frederic Rzewski's To the Earth (1985) is a Homeric poem accompanied by earthen flowerpots played with the fingertips. This work has been especially successful among percussionists and audiences owing to an ecological sensibility expressed in both the text and the instrument selection, and the accessible, everyday origin of the percussion instruments (Schick, 2006). Other notable works from this decade include Lost and Found (1985) by Frederic Rzewski, and Riuti: Rödungen und Wüstungen (1981), by Walter Zimmermann. An extensive list of more recent works may be found in Whiting Smith (2012).

Since then, the repertoire for solo speaking percussionist in particular has grown, much more so than for any other instrument. Because percussion music within the Western concert tradition is phenomenon of the modern era (the first work for concert percussion alone was Ionisation (1930), by Edgard Varèse), the ethos of percussionists in general has been to emphasise contemporary repertoire. And percussionists, by nature, are not specialists on an instrument but called upon to perform music on an endless variety of objects, from drums, bells, metals, wooden blocks, and keyboard-type instruments from cultures all around the world, to found objects that were not intended as instruments at all. The incorporation of voice, then, may be just one more sound-making object to be incorporated into the percussion instrumentarium. Percussionist Bonnie Whiting Smith (2012) further explores the resonances between percussion playing and vocalisation. There is a parallel between the simple and self-evident method of percussion sound production, "you hit something and then it speaks", and the universality of vocal communication (p. 7). What's more, she states, "percussion instruments are set pieces and props: visual and theatrical elements as well as musical elements," (p. 11), so there is a resonance between the storytelling implicit in delivering a spoken text and the theatrical physicality of percussion performance. Finally, also, the tremendous variety of sound-making devices available to percussionists makes possible the direct realisation of parallels between instrumental sound and the timbres and rhythms of speech.

\section{Composing Zaum Box}

I approached the composition of Zaum Box as an imaginative inhabiting of the frenetic joy, passion and optimism of the brief utopian moment of the Russian cubo-futurists, before the Russian artistic avantgarde was subsumed by a political imperative. It would be an effort to intersect my prior compositional practice and musical language with a playful, spontaneous approach drawing on zaum, constructivist visual design, and an openness to theatrical realisation facilitated by indeterminacies in instrumentation and the manner of vocal recitation. While no physical motions other than those required to produce sounds are specified in the score, as they are in more overtly theatrical works such as those by George Aperghis, the player is encouraged to incorporate theatrical interpretations. In fact, Katelyn Rose King's method of interpreting the works involved inventing a character that she would portray with each work and imagining how that character would inform her playing style, instrument selections, vocal quality, her motion and facial expressions, and her overall demeanour. In some works, the musical content suggests characterisations, such as Ta sa maye, in which the petals of a flower are plucked (in the manner of the children's game of 'she loves me, she loves me not') as the poem is recited. But in most of the works, developing a characterization is left entirely to the performer.

Some compositions in Zaum Box explore humour and unconventional or awkward sound sources. Dyr bul shchyl is performed with wire brushes waved vigorously in the air and only sometimes striking an unspecified object selected by the performer. While the use of brushes suggests snare drum 
as a natural choice of instrument, the premiere was performed by Alexv Rolfe on a watermelon. In Kho bo ro, a study in dynamism and trajectory (Figure 1), harmonies generated by a process of permutation over a two-octave pitch space are played as loudly as possible on crotales with wire brushes - entirely the wrong implement for playing loudly — obscuring those carefully crafted pitch structures to an absurd degree and calling for wildly exaggerated body movements. This work also illustrates the playfulness of the design of the scores, and the manner in which the visual appearance of the original poem informed both the music but the visual design of the score. The original poem, written as a column penetrated by abstract geometric forms suggestive of dynamic motion, is reproduced in the upper left of the one-page score. (Each of the scores in Zaum Box includes a reproduction of the original poetry and a transliteration into English, although not always on the same page as the music). The abstract forms in the poem inspire the angular layout of the two score systems, while dynamics in the voice part are indicated by the size of the printed text rather than with conventional dynamic symbols (such as $p$ or $f$ ). In this short work, a persistent deceleration in the vocal part is juxtaposed against an instrument line which decelerates and then symmetrically accelerates.

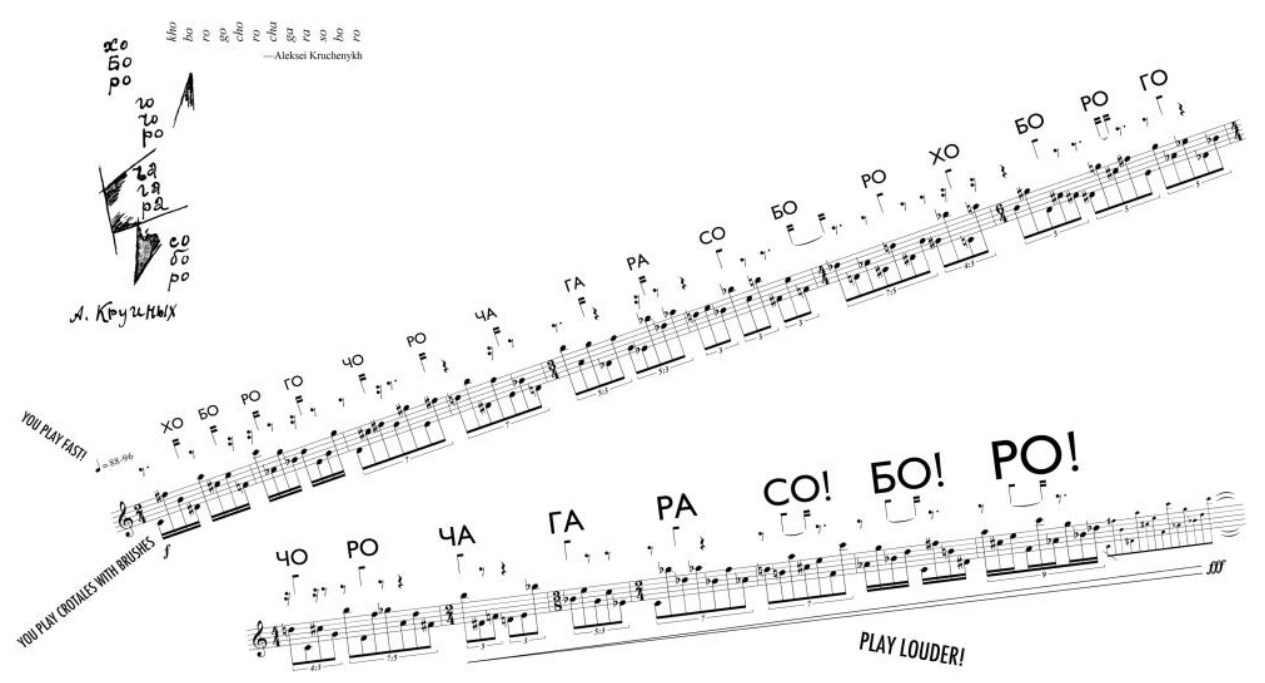

Figure 1. Kho bo ro, from Zaum Box, with poetry by Aleksei Kruchenykh from Learn, Artists! (1917).

In my setting of Telephon-no. $2 B-12 z$, a typographically stunning evocation of a telephone conversation by Vasily Kamensky (1914), the performer uses a recording application on their smartphone to create and perform a real-time telephone conversation. The instrumentation draws from instruments that are used in other works from the set. So, when multiple works are performed on the same concert, this movement may be performed by moving around the different setups, walking just as they would if having a phone conversation. The use of the phone as well as the implication of physical motion invite a theatrical interpretation. Because operating the phone as a recording and playback device in performance is logistically difficult, pre-recording and playing back audio segments using a second performer operating a playback device offstage is also permitted.

Two compositions, Pye Ry Zat and Vnafti, are exercises in automatic composition, each composed from beginning to end in a single, brief sitting with no editorial revision, using the prearranged harmonic materials derived from those of Kho bo ro. The compositions were then handwritten on angularly displaced staff fragments emulating the handwritten appearance of the original poetry in Kruchenykh's booklet F/Nagt (1918) and its manner of presentation within abstract linear forms suggestive of dynamic motion. Both compositions share the same notational layout indicating an indeterminate instrumentation of a keyboard instrument and five objects, and may be realised with the same instruments or entirely different ones. The range of the keyboard part in both works is small enough to played on a glockenspiel or melodica and can therefore be realised on these or any larger instruments. 
In Frot fron it, the chimeric being of the speaking percussionist becomes the subject. It is a concerto in four movements in which the performer's voice is the soloist and their instrument-playing body is the orchestra. The elaborate vocal part deconstructs the text into phonemes that are deployed into rhythmically elaborate gestures, of a difficulty suitable for a concerto soloist. In the first movement, the percussion accompanies an elaborate exposition of the fricative sounds of the first line of the text ('frot fron it') in rhythmic counterpoint (Figure 2). In the second, the text evokes a tribal scene in broken Russian and is spoken in free rhythm over repeating rhythmic patterns. The third is a cadenza for solo voice, combining the elaborate fricatives of the first movement with vocal evocations of instrumental sounds. Finally, in the fourth movement, played entirely with bare hands on percussion, the voice continues to evoke the sounds of the accompanying instruments (Figure 3) while the instruments emulate the sounds of the zaum text, merging soloist and orchestra into one sound-making entity. By the end, through the associations of vocal and instrumental sounds established through the course of the movement, the instruments are able to 'speak' the poetry in counterpoint with the voice (Figure 4).

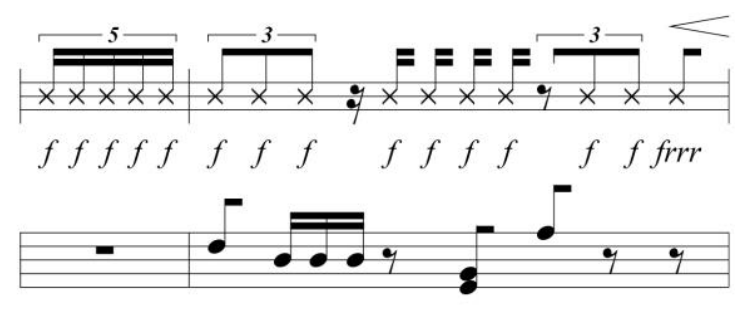

Figure 2. Excerpt from the first movement of Frot fron it from Zaum Box, with vocal part on the upper staff and percussion on the lower staff. The five percussion instruments are, from the top line of the staff down: squeaking metal, guiro, sandpaper block, rattle and low drum.

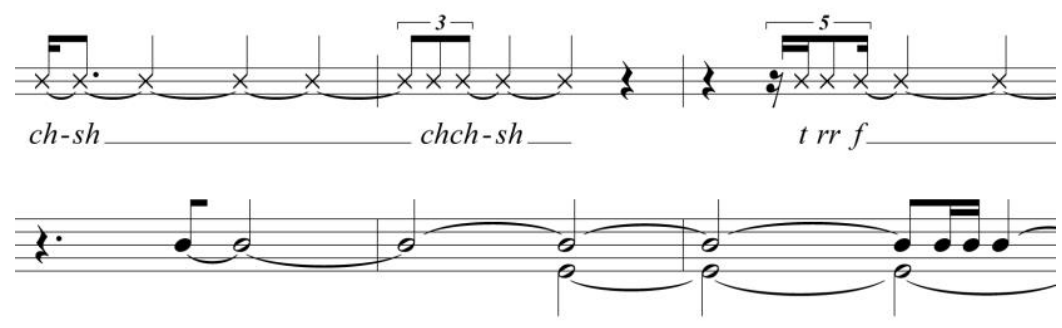

Figure 3. Excerpt from the fourth movement of Frot fron it from Zaum Box, where the voice imitates the sounds of the percussion instruments and the instruments begin to echo vocal sounds.

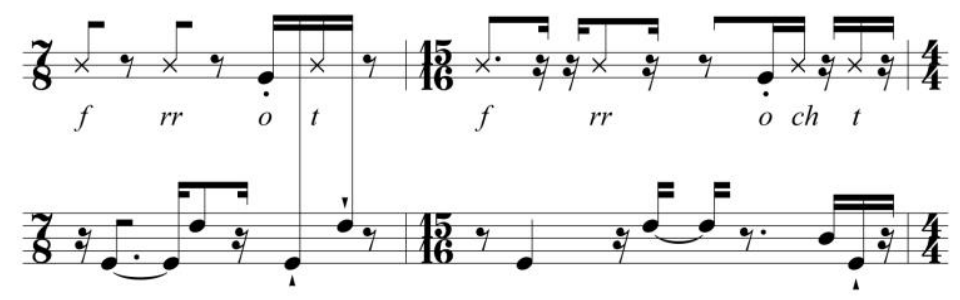

Figure 4. Excerpt from the fourth movement of Frot fron it from Zaum Box, where the instruments 'speak' the poetry in rhythmic counterpoint with the voice.

While much zaum poetry can be conventionally read, left-to-right, top-to-bottom, Kruchenykh's $S-K-L$ (my title, derived from the topmost letters of an untitled image on a page from Learn, Artists!, published in 1917) presents a set of letters embedded into geometric forms with no clear linear presentation or unambiguous means to sound out the poetry. This ambiguous and non-linear unreadability is musically realised as an indeterminate score-diagram (Figure 5). The performer must select instruments that can be played, as well as activated by the voice or in some way modulated by 
the sound of the voice. The score operates as a zaum-generator with vocal and instrumental sounds. Individual letters may be pronounced as through reciting the alphabet ("es-ka-el") or as phonemes. If treated as phonemes and read in succession, they may be strung together to form new zaum words (e.g. 'sklyu'). Rather than resolve the problem of unreadability by arbitrarily selecting an ordering of sounds, the diagram enables the performer to take multiple pathways through a space of possible realisations.
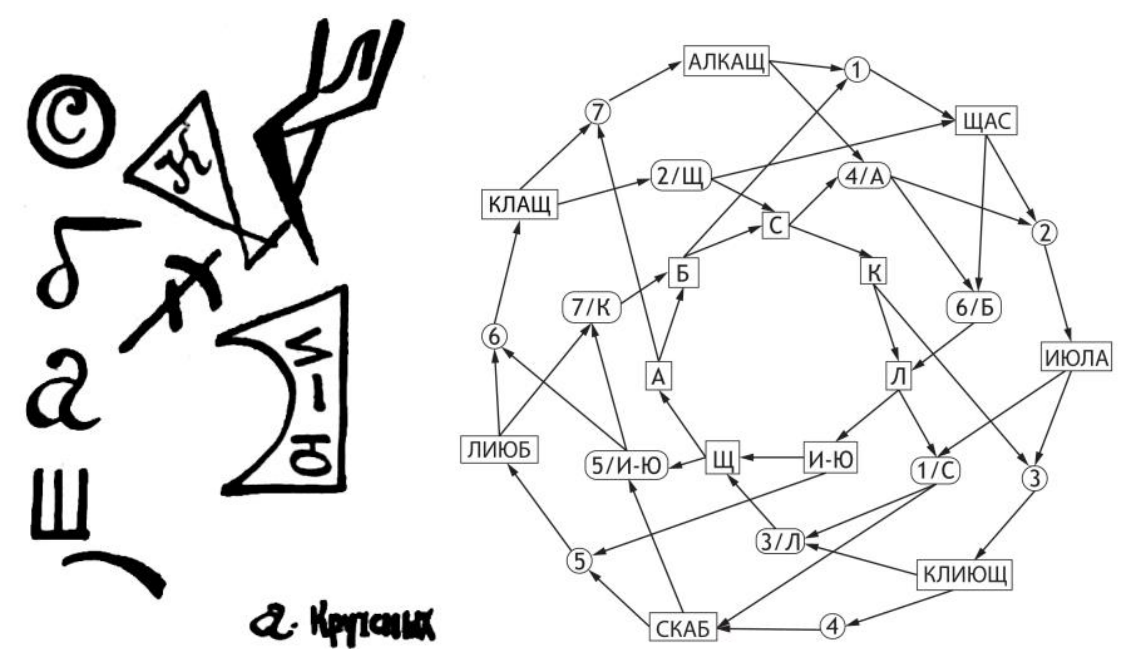

Figure 5. Page from Learn, Artists! (1917) by Aleksei Kruchenykh (left), and score diagram of $S$-K-L from Zaum Box.

\section{Production and Realisation}

The production of the ten scores in Zaum Box emulated the short-run productions of the zaum poets, with a nod towards the transformation of those booklets into art objects that took place later in the $20^{\text {th }}$ century. The scores were prepared as digital images, and each work was printed in large format on distinctly coloured and textured paper, such as tinted watercolour paper, vellum, faux parchment, and metallic card stock. One work was enclosed in a separate envelope, and another other bound into a booklet. The entire collection of ten scores, along with covers, a certificate of authenticity in an airmail envelope stamped with late Soviet-era stamps, and a USB flash drive with PDF versions of the scores, a pronunciation guide and an extended program note, were enclosed in an archival photo box (Figure 6). Twenty-five boxes were produced and sold, and one was donated to the Athenaeum Music \& Arts Library, a private library in La Jolla, California. ${ }^{3}$ After the final box was sold, the work may now be obtained only as a digital document. The limited-edition box set is a proposition of the musical score as an art object with aura and value, in an era when the practical expediency of emailing scores as PDFs threatens to entirely instrumentalise the score-as-object and reduce its material value to zero. 


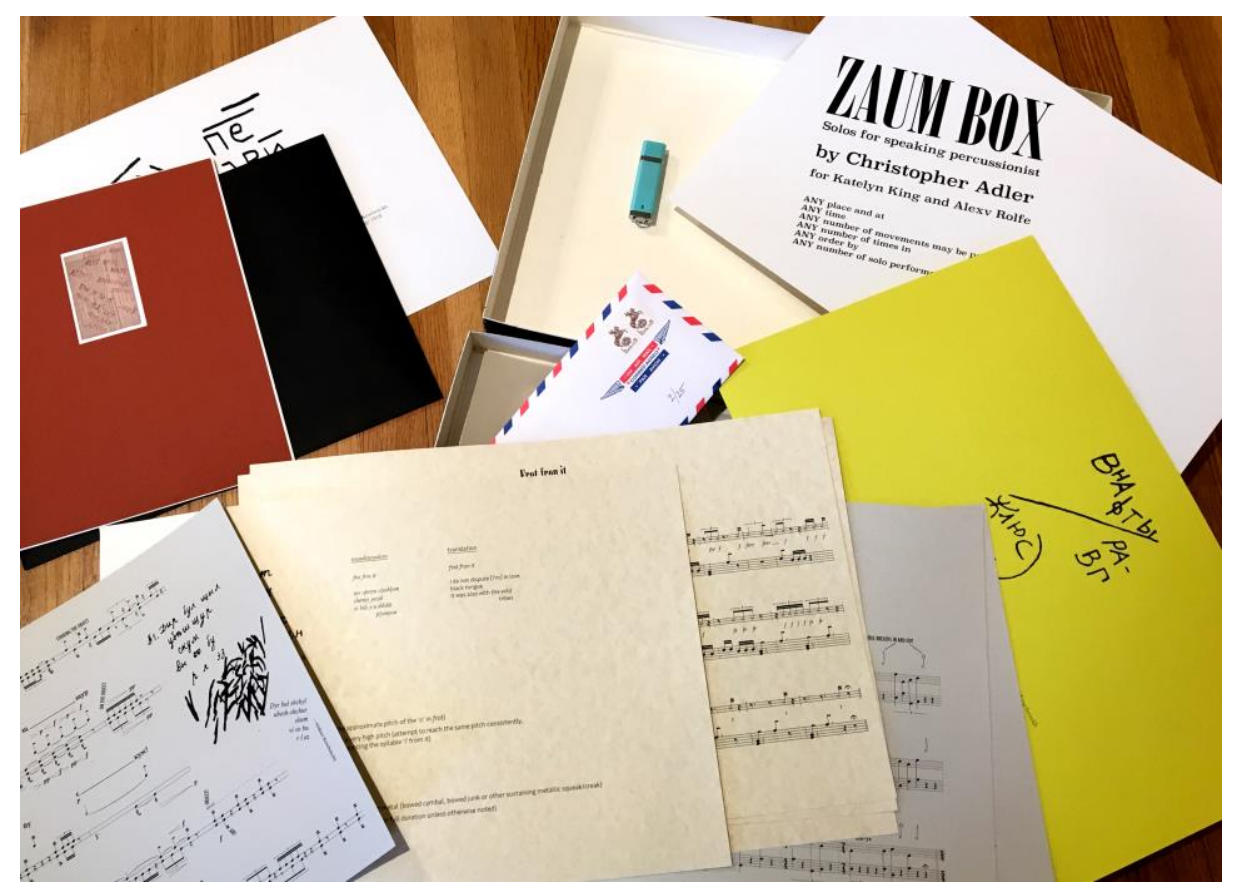

Figure 6. Contents of the Zaum Box limited edition box set. Photo by the author.

The final phase of the project was to create a video realisation of all ten compositions. Realisations were developed and performed by percussionist Katelyn Rose King, and these were recorded over a period of four days by videographer Ute Freund and sound recordist Christoph Utzinger at a flexible artist space Berlin, Germany. Staging, lighting, camera angles and movements, scene composition and editing were conceived as emanating from the visual designs of the scores, which in turn were inspired by the visual design of the original zaum poetry. For Ta sa maye, for example, Katelyn conveyed a sense of intimacy and interiority by performing seated on the floor, while Freund emphasised this intimacy by filming a series of handheld close-ups of both the performer and her percussion setup from a variety of creative angles (Figure 7).

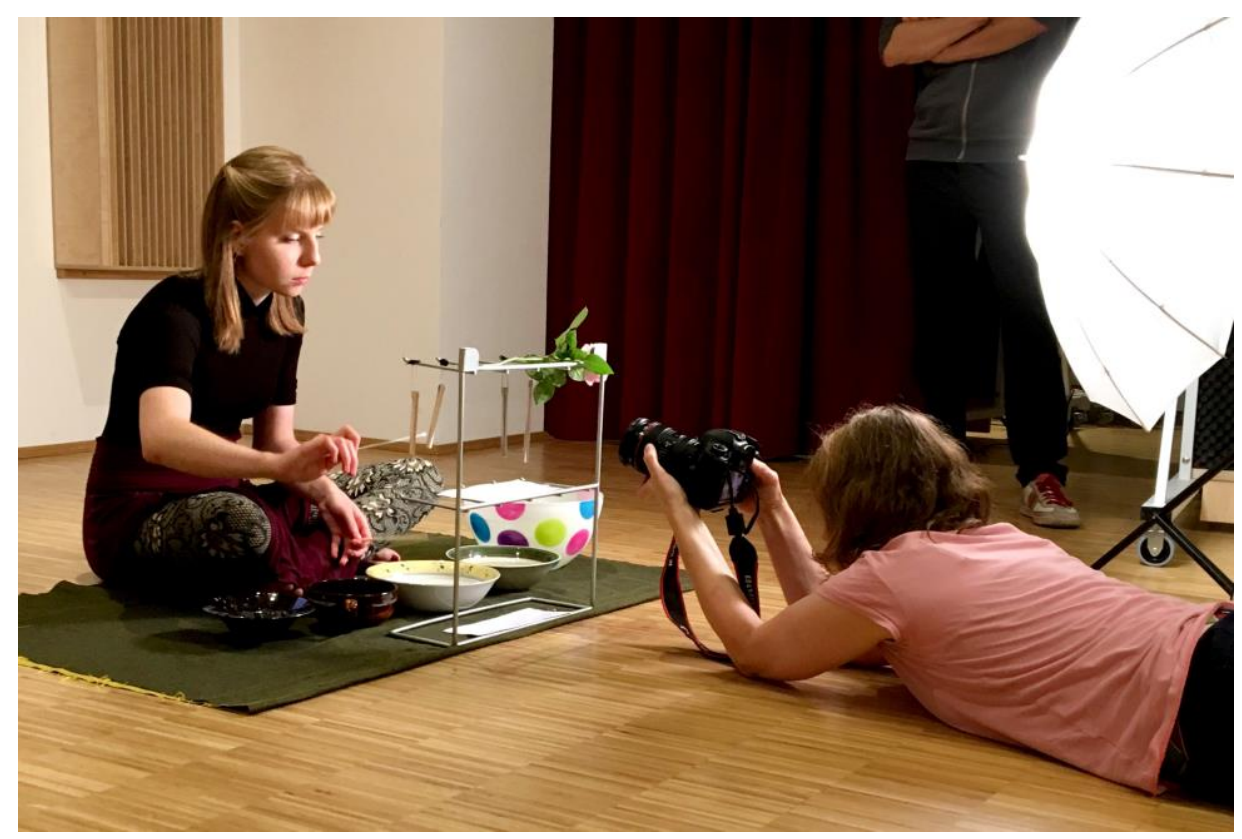

Figure 7. Katelyn Rose Ring performing Ta sa maye from Zaum Box, filmed by Ute Freund, with sound recordist Christoph Utzinger in the background. Photo by the author. 
Freund designed graphic title sequences for each video, beginning with the words "ZAUM BOX", in the same distinctively elongated font as on the title page of the box set, filling the screen and providing a uniform appearance, segueing to uniquely arranged or animated titles of the individual works, reflecting the musical character or visual design of each. In Learn, Artists!, by Kruchenykh, the poem Vnafti is handwritten around a large diagonal slash that cuts across the page. In the musical work Vnafti, the slash appears both as a musical gesture of a rapid arpeggio, and in the layout of the score where, not unlike Kho bo ro, staff systems cut across the page at an angle. In the video realisation, the camera is tipped at an angle so that the vibraphone played by Katelyn cuts across the screen at a comparable angle. And for the title sequence, the words "ZAUM BOX" fill the screen and then suddenly tumble to an angle mirroring that of the vibraphone (Figure 8, upper left and upper right).

The complete set of ten videos has been released on-line (Adler \& King, 2016) to publicly present the work and to provide a reference for future performers of the work, which is crucial given that the scores leave many aspects of performance realisation unspecified.
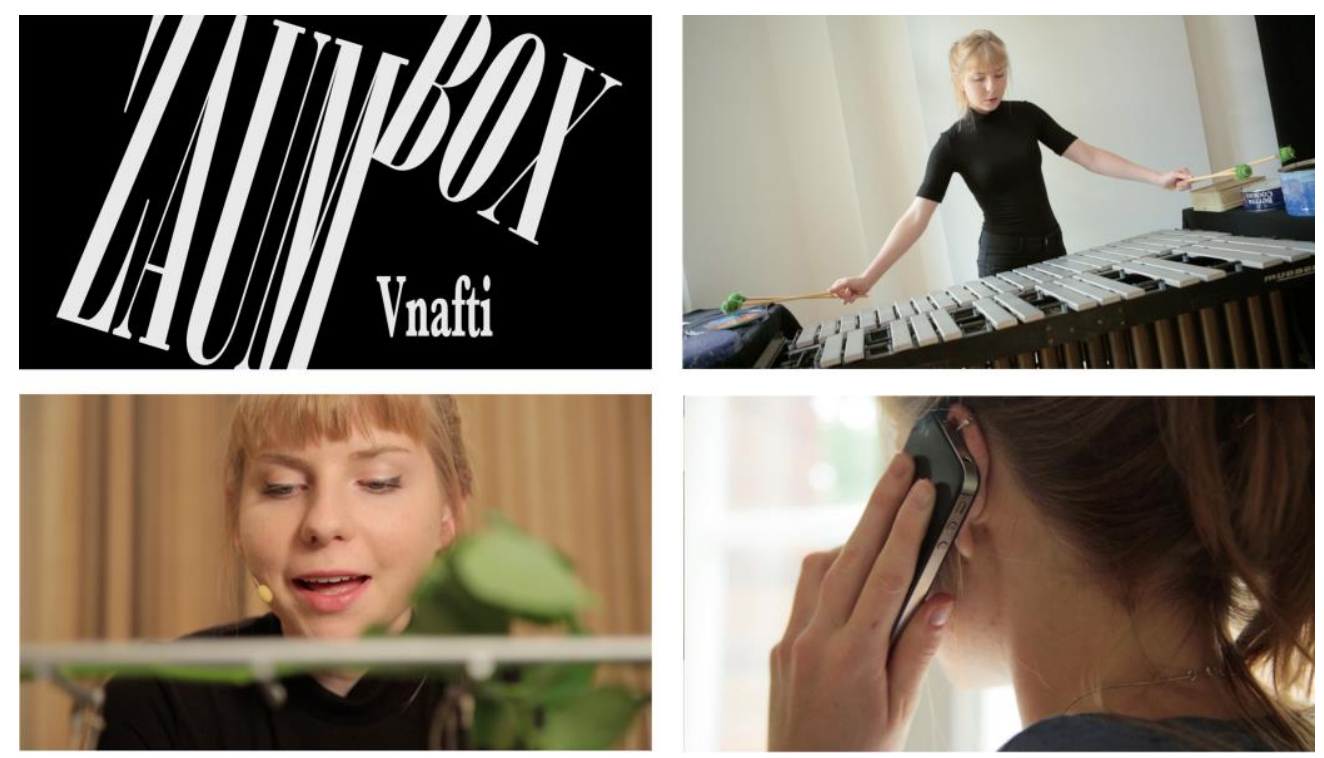

Figure 8: Video stills from Zaum Box, with percussionist Katelyn Rose King and cinematography and titles by Ute Freund. Clockwise from upper left: title animation of Vnafti, the fixed camera angle for Vnafti, a scene from Telephon-no. $2 B-12 z$, a handheld close-up shot from Ta sa maye.

\section{Conclusion}

Zaum Box represents a collaborative, research-based project in contemporary music composition, bridging sources, inspirations and genres from the $20^{\text {th }}$-century avant-garde, including Russian futurism, Fluxus, post-tonal music theory, indeterminacy, nonconventional notation and the subgenre of music for speaking performer. In published form, the work is presented as a collectible artistic object as well as a musical work to be realised. In performance realisation, the flexibility and theatricality permit presentation as a concert work, as a staged work of musical theatre, or as staged video production. The work joins an emerging body of scholarship in helping bring to prominence a little known but remarkably forward-thinking movement of the avant-garde, that had been almost impossible to research until following the collapse of the Soviet Union.

\section{Endnotes}

${ }^{1}$ Subsequent phases of the project include the documentation of the project in this article, and the organisation of the event Future Beyond Reason on October 24, 2019 at the University of San Diego in San Diego, California. The event included a panel of presentations by the author, Nancy Perloff, and Charissa Noble as well as a concert performance of the complete Zaum Box realised by percussionist Jordan Curcuruto. 
${ }^{2}$ The use of lowercase lettering is in the original. Punctuation has been corrected by the author to be consistent with the original.

3 Additional publicly available copies are located at the University of Washington Music Library in Seattle, Washington, and at the Royal Conservatory of Brussels in Belgium.

\section{Acknowledgements}

The production of scores and video recordings was supported in part by a grant from the University of San Diego College of Arts and Sciences. I sincerely thank Katelyn Rose King and Alexv Rolfe for initiating this collaboration, and Katelyn for her dedication to realising the work in its entirety. And I thank Ute Freund and Christoph Utzinger for their artistry in realizing the videos. Finally, I thank all the performers, libraries and collectors who purchased the limited-edition box set and thus helped to fund the production of this project.

\section{References}

Adler, C. (2007). Reflections on cross-cultural composition. In J. Zorn (Ed.), Arcana II: Musicians on music (pp. 9-35). Granary Books/Hips Road.

Adler, C. (2012). Mathematics, automation and intuition in Signals Intelligence for percussion. Sonic Ideas 4(1), 9-15.

Adler, C. (2016). Zaum box. Liber Pulveris Press.

Adler, C. \& King, K. (2016). Zaum box (playlist of ten videos). https://www.youtube.com/watch?list=PL1euiR8RcG1didrOCWKAcQYbIv3q8mQ6I\&v=xmrC-iZiscE

Burmesier, R., Oberhofer, M. \& Francini, E.T. (2016). Dada Africa: Dialogue with the other. Scheidegger und Spiess.

Groys, B. (2011). The total art of Stalinism: Avant-garde, aesthetic dictatorship, and beyond. Verso.

Harte, T. (2009). Fast forward: The aesthetics and ideology of speed in Russian avant-garde culture, 19101930. University of Wisconsin Press.

Higgins, H. (2002). Fluxus experience. University of California Press.

Janecek, G. (1996). Zaum: The transrational poetry of Russian futurism. San Diego State University Press. Kamensky, V. (1914). Tango s korovami [Tango with cows]. First Journal of Russian Futurists.

Kruchenykh, A. \& Khlebnikov, V. (1988). Slovo kak takovoe [The word as such]. In A. Lawton \& H. Eagle, (Eds., trans.), Russian futurism through its manifestoes, 1912-1928 (pp. 57-62). Cornell University Press.

Kruchenykh, A. \& Larionov, M. F. (1913). Pomada. G. Kuz'mina and S. Dolinskago.

Kruchenykh, A. (1917). Uchites' khudogi. [Learn, artists!]. n.p.

Kruchenykh, A. (1918). F/Nagt. n.p.

Perloff, N. (2016). Explodity: Sound, image, and word in Russian futurist book art. Getty Research Institute.

Schick, S. (2006). The percussionist's art: Same bed, different dreams. University of Rochester Press.

Whiting Smith, B. A. (2012). Narratives on narratives, from utterance to stories: Finding a context for the speaking percussionist [Doctoral dissertation, University of California San Diego]. https://escholarship.org/uc/item/2c92h7p0

Zdanevich, I. (1923). LidantIU fAram [Lidantiu as beacon]. $41^{\circ}$.

\section{Biography}

Christopher Adler is a composer, performer and improviser living in San Diego, California. His compositions encompass cross-culturally hybrid forms drawn from contemporary concert music and traditional musics of Thailand and Laos, and the application of mathematics to composition. His recent works have concerned Russian futurism and classical Latin epic poetry. He is a foremost performer of traditional and new music for the khaen, a free-reed mouth organ from Laos and Northeast Thailand, and has promoted the khaen as a concert instrument by commissioning, performing and recording pieces by composers from around the world. He is a Professor of Music at the University of San Diego, and has degrees in music composition from Duke University and the Massachusetts Institute of Technology. www.christopheradler.com 